\title{
Screening for BRCAl and BRCA2 mutations in breast cancer patients from Mexico: The public health perspective
}

\author{
Steven A Narod, MD. ${ }^{(1)}$
}

\begin{abstract}
Narod SA.
Screening for BRCAI and BRCA2 mutations in breast cancer patients from Mexico: The public health perspective. Salud Publica Mex 2009;5 I suppl 2:SI9I-SI 96.
\end{abstract}

\begin{abstract}
Genetic testing for mutations in BRCAI and BRCA2 has potentially important public health implications. Through judicious testing of women believed to be at high risk for early-onset breast cancer and for ovarian cancer, it is possible to identify highly-predisposed women prior to the development of cancer. Current preventive options include preventive mastectomy, preventive oophorectomy, tamoxifen and oral contraceptives. The ability to offer genetic testing in Mexico on a widespread level is enhanced if the common founder mutations in the two genes can be discovered or if the cost of genetic sequencing is reduced. It is important that a genetic testing service be a multi-disciplinary effort with co-ordinated follow-up.
\end{abstract}

Key words: breast cancer; hereditary; BRCAI; BRCA2; Mexico

\section{Narod SA.}

Tamizaje de BRCAI y BRCA2 en pacientes con cáncer de mama en México: perspectiva de la salud pública. Salud Publica Mex 2009;5 I supl 2:SI9I-SI96.

\section{Resumen}

Los exámenes genéticos para las mutaciones en el BRCA I y el BRCA 2 tienen potencialmente una importante implicación en materia de salud pública.A través de exámenes juiciosos en mujeres en las que se cree que tienen un riesgo alto de padecer cáncer de mama y de ovario de inicio temprano, es posible identificar mujeres con una alta predisposición antes de que éstas desarrollen el cáncer de mama. Dentro de las medidas preventivas actuales se incluyen la mastectomía, la ooforectomía, el tamoxifen y los anticonceptivos orales. En México, la habilidad para ofrecer exámenes genéticos a nivel poblacional se vería favorecida si se pudiesen descubrir las mutaciones fundadoras en los dos genes o si el costo del secuenciamiento genético fuese reducido. Es muy importante que el servicio de los exámenes genéticos sea el resultado de un esfuerzo multidisciplinario con seguimiento coordinado de los pacientes.

Palabras clave: cáncer de mama; hereditario;BRCAI;BRCA2; México
$\mathrm{T}_{\mathrm{n}}^{\mathrm{h}}$ The rate of breast cancer in women from Mexico is much less than that of the United States, but breast cancer is still among the most common causes of death in Mexican women between the ages of 40 and 69 years. Mexico is the twelfth largest country in the world, with 110000000 inhabitants and approximately 14000 new cases of breast cancer are diagnosed each year. The contribution of genetic factors to the burden of breast cancer in Mexico has not been studied.

There are several genes which confer a heightened predisposition to breast cancer, but only two of these, BRCA1 and BRCA2, currently are candidates for clinical

(I) Women's College Research Institute, University of Toronto, Canada.

Received on: November 13,2008 - Accepted on: January 8, 2009

Address reprint requests to: Dr. Steven Narod. Centre for Research in Women's Health, 790 Bay Street, Toronto, Ontario M5G IN8.

Email: steven.narod@wchospital.ca 
genetic testing. Screening for BRCA1 and BRCA2 is common in the United States, in Canada, in much of western Europe, in Poland and in Israel, but is rare in most Latin American countries. Approximately $10 \%$ of women who are diagnosed with breast cancer report a family history of the condition, and for some, a germ-line mutation in one of these two genes is responsible. However, among women with breast cancer and a mutation in BRCA1 or BRCA2, a large proportion do not have a significant family history of cancer and therefore it is not always reasonable to restrict genetic testing to familial cases.

Furthermore, women with a strong family history of breast cancer and a negative test result remain at high risk of breast cancer, albeit lower than that seen in women with mutations. Recently, we estimated that among patients in our clinic who had a negative genetic test result, the risk of breast cancer was about four times greater than expected. ${ }^{1}$

The lifetime risk of breast cancer in women who carry a BRCA1 or BRCA2 mutation is about $80 \%^{2}$ but the absolute risk may vary according to the country of residence. Characteristics of hereditary breast cancer include a young at age at onset (typically between ages 30 and 50) and/or multiple cases of early-onset breast cancer or ovarian cancer in the family. ${ }^{3}$ In addition, certain features of the breast cancer itself indicate that a BRCA1 mutation might be present. The majority of breast cancers in women with a BRCA1 mutation are triple-negative (i.e. negative for estrogen receptor, progesterone receptor and HER2/neu). ${ }^{4,5}$ However, only about ten percent of all women with early-onset triple-negative breast cancer carry a BRCA1 mutation. ${ }^{*}$ The breast cancers that arise in women with BRCA2 mutations by and large resemble their non-hereditary counterparts.

The prevalence of BRCA1 and BRCA2 mutations varies by country and by ethnic group. It is hard to estimate the mutation prevalence directly, because few surveys have been done in the general population (the mutation rates are too low and testing is too costly). The (combined) prevalence of mutations is approximately $0.3 \%$ in North America, and is $2.5 \%$ in Jewish women in Israel or the United States. ${ }^{6}$ No prevalence surveys have been conducted in Latin American countries.

\section{Who to test?}

The ability to predict the presence of a BRCA1 or a BRCA2 mutation can be estimated to a large extent by

\footnotetext{
* Young RS, Pilarski R Donenberg T et al. The Prevalence of BRCA1 Mutations Among Young Women with Triple-Negative Breast Cancer (submitted). Breast Cancer Research.
}

examining the age-of-onset of breast cancer in the patient, the family history, the ethnic group and the associated pathology. It is prudent that all four of these factors be included in an assessment protocol when deciding whether or not an individual woman with breast cancer should be tested for a mutation. In general, it is best to first test an affected woman in the family, and if she is positive, then to continue on to test unaffected women. This is based on the assumption that an affected woman is more likely to harbor a mutation than is an unaffected woman. Furthermore, it is difficult to interpret the meaning of a negative test result for an unaffected woman if it is not known if a mutation is present in the family. In contrast, if a woman with breast cancer in a family is found to carry a mutation, then unaffected relatives who do not carry the mutation can be assumed be at average risk, and counselled accordingly.

In the absence of a family history, in our clinic we offer genetic testing to all women with triple-negative breast cancer diagnosed below age forty, ${ }^{*}$ to all women with invasive ovarian cancer ${ }^{7}$ and to all Jewish women with breast cancer. ${ }^{8}$ In the absence of one of these three indications, we test women when a significant family history is present (two or more cases of early-onset breast cancer (less than age 50) or ovarian cancer at any age). Testing is gaining acceptance worldwide because of the increasing options available to women with a mutation, and because of the development of novel, individualized, cancer therapies.

\section{Founder mutations}

In some ethnic groups, the presence of one or more founder mutations makes genetic testing simple and inexpensive. This means that the majority of women with a mutation will have one of a small number of mutations (usually less than ten). It is therefore reasonable to look for only these mutations in women who qualify for genetic testing. In some cases (i.e., if a woman has a negative screening test for founder mutations but has a strong family history) more extensive testing is warranted. Countries and ethnic groups with founder mutations, and where limited testing is the standard protocol, include French-Canadians; ${ }^{9}$ Askhkenazi Jews, ${ }^{10,8}$ and Poland. ${ }^{11}$

It is hoped that founder mutations will be found in Latin American countries in order that genetic testing can be introduced on a wide scale and so the benefits of genetic advances can be made available to the greatest number of women. Currently, in Mexico and other Latin-American countries, genetic testing is available in the private health care system to women with adequate resources to pay. Given that the cost of commercial test- 
ing is approximately 3000 dollars US for the complete sequencing of both genes, genetic testing is currently beyond the reach of most women. This situation could change if founder mutations could be established. To this end, efforts are underway to determine the frequency and spectrum of BRCA1 and BRCA2 mutations in a number of Central American and South American countries, including Mexico. To establish the presence of a founder mutation it is necessary to identify the distribution of mutations in a large sample of unrelated affected individuals. It is also necessary to establish that the founder mutations account for the majority of women with mutations in the population. Of course, it is possible to introduce genetic testing into a population without founder mutations, but the cost of testing will be many times higher. It is hoped that cost of sequencing will decline sufficiently in the near future to make full-gene sequencing a viable alternative to looking for founder mutations.

Studies of mutations have been conducted in Brazil, Cuba, Colombia, Mexico ${ }^{12,13}$ and Chile. In some cases, mutation surveys have been done on a small number of families with multiple members affected with breast or ovarian cancer. These studies have the advantage of being inexpensive and may be instrumental in identifying the key mutations that are present in a country. However, in order to estimate the genetic burden of breast cancer in a particular country and to properly characterize patients with and without mutations, it is preferable to sequence a large number of unselected breast cancer cases and to obtain details of the family history of each of these.

\section{Brazil}

In Brazil, we looked for deleterious BRCA1 and BRCA2 mutation in 402 unselected Brazilian women with breast cancer. ${ }^{14}$ Overall, nine mutations were identified (six in BRCA1 and three in BRCA2) representing 2.3\% of the total. The most common mutation, 5382insC in BRCA1, was seen five times and accounted for $56 \%$ of all identified mutations. Asecond mutation, in BRCA2 (6633del5) was seen in two unrelated women. These data support the position that genetic testing for common founder mutations be offered to women in Brazil with breast cancer before the age of 50 or with a family history of breast or ovarian cancer in a first-degree relative. Interestingly, Dufloth et al. identified the same 5382insC BRCA1 mutation in a breast cancer family from São Paulo and found a BRCA2 mutation (S2219X) in two families. ${ }^{15}$ The 5382insC mutation is the most common mutation identified worldwide and is found both among Ashkenazi Jews and women of Slavic origin. It has also been seen in a family from Costa Rica (unpublished data). Haplotype analysis confirms a common origin with the European mutation (WD Foulkes, personal communication).

\section{Colombia}

Torres and colleagues ${ }^{16}$ studied familial cases of breast cancer in Bogota, Colombia. They identified 13 deleterious mutations among 53 families (24\%), eight in BRCA1 and five in BRCA2. The two recurrent BRCA1 mutations, 3450 delCAAG and A1708E, accounted for all eight BRCA1 mutations identified. The 3034 delACAA BRCA2 mutation accounted for two of the five BRCA2 mutations.

\section{Chile}

Two mutation surveys have been completed in Chile. Jara et al. found seven BRCA1 mutations and three BRCA2 mutations in 64 breast cancer families from Chile. ${ }^{17}$ All ten mutations were different. Gallardo et al. identified three BRCA1 mutations and five BRCA2 mutations in 54 Chilean breast/ ovarian cancer families. A single recurrent BRCA1 mutation (Q1273X) was seen (in two families). ${ }^{18}$

\section{Cuba}

Cuba is an island nation of approximately 11000000 people. We studied the prevalence of BRCA1 and BRCA2 mutations women with breast cancer from a large public hospital in Havana. ${ }^{19}$ Among 307 unselected women with breast cancer, eight mutations were identified (seven in BRCA2 and one in BRCA1) representing $2.6 \%$ of the total, including $10 \%$ of familial cases and $10 \%$ of cases under age forty. Only one mutation was found on more that one occasion (BRCA2 3394C > T). Given that no clear example of a founder mutation was found, it appears that there is little chance for developing a rapid and inexpensive clinical screening test in Cuba.

\section{Hispanic women in the United States}

Three mutation surveys have been done in Latina women in the United States. Two of the studies originated in California and one was from Texas. A large proportion of the Latina population in California and Texas have their origins in Mexico, and therefore these studies have relevance for the Mexican population. It is not yet clear, however, to what extent Mexican emigrants to the United States are representative of the Mexican population at large. At the MD Anderson Cancer Center 
in Houston, Texas, 14 Hispanic women with familial breast cancer of 78 women tested were found to carry a mutation (18\%). ${ }^{20}$ The 185delAG BRCA1 mutation was seen in four different families. In a study from Northern California, John et al. found a BRCA1 mutation in 21 of $393(5.3 \%)$ Hispanic women with breast cancer diagnosed before age $65 .{ }^{21}$ After adjusting for family history, they estimate the mutation prevalence among unselected cases to be $3.5 \%$. They also saw the $185 \mathrm{del} A \mathrm{G}$ BRCA1 mutation (on five occasions). Weitzel and colleagues ${ }^{22}$ studied 110 unrelated Latina women at high risk of breast/ ovarian cancer in Los Angeles. 34 of the 110 women had a mutation $(31 \%)$; of these 18 were of Mexican descent. Four mutations were seen more than once in women with Mexican origins: BRCA1 185delAG (four times); BRCA1 R1443X (three times); 2552delC (2 times); 3492insT (2 times). This group later reported a founder deletion in four unrelated families of Mexican origin. ${ }^{23}$ The deletion encompassed exons 9 through 12. It is not yet known what is the prevalence of these, and other mutations among unselected women of Mexican origin with breast cancer.

\section{Prevention and treatment}

Ultimately, the benefit from genetic testing in any population comes from the ability to reduce the incidence of, or mortality from, breast cancer. Goals of genetic testing include reducing the number of incident cancers, detecting cancer at an early stage through screening and offering optimum, individualised treatment.

Current strategies for the primary prevention of breast cancer include prophylactic mastectomy and chemoprevention with tamoxifen. The strongest degree of risk reduction is obtained with preventive mastectomy (greater than 95\% protection). However, this option is chosen by only relatively few women, due to concerns about body image and social and cultural factors. It is also important that the medical community is supportive of the decision to undergo preventive surgery. The satisfaction of a woman with her choice to undergo preventive mastectomy is enhanced if she is in a supportive environment and if breast reconstruction is available to her. Prophylactic oophorectomy is associated with an $80 \%$ reduction in the risk of ovarian cancer ${ }^{24}$ and (if done prior to age 45) and a 50\% reduction in the risk of breast cancer ${ }^{25}$ We have recently shown that hormone replacement therapy may be given after preventive oophrectomy to alleviate the symptoms of menopause, without raising the risk of breast cancer. Tamoxifen treatment is associated with a 50-70\% reduction in the risk of contralateral breast cancer. ${ }^{26}$ It is not known to what extent tamoxifen reduces the risk of first primary breast cancer, and to date, acceptance of tamoxifen chemoprevention has not been widespread. ${ }^{27}$ Breastfeeding has been shown to be protective in BRCA1 carriers for both breast and ovarian cancer. ${ }^{28,29} \mathrm{BRCA} 1$ carriers should be encouraged to breastfeed for as long as possible.

\section{Screening}

Traditionally, screening for breast cancer has included mammography, breast self examination and clinical breast examination. In the United States and Canada, MRI screening has been added to these because observational trials have consistently shown that the sensitivity of MRI screening is higher than that of any other screening modality. ${ }^{30}$ However, it has not yet been shown that regular MRI screening reduces mortality from breast cancer. In Mexico, if MRI screening is not readily available to mutation carriers, then closer attention should be placed on means of primary prevention, such as tamoxifen and preventive mastectomy. Mammography alone should not be encouraged as an alternative to preventive surgery, tamoxifen or MRI.

\section{Individualised treatment}

Physicians are also interested in identification of carriers of BRCA1 and BRCA2 mutations in order to offer optimum treatment. Treatment for the mutation carrier should take into account the very high risks of contralateral breast cancer and of ovarian cancer that follow an initial diagnosis of breast cancer. To this end, if a woman with breast cancer has a BRCA1 or BRCA2 mutation, she will be offered more extensive surgery (usually bilateral mastectomy) in order to prevent a second primary or a contralateral breast cancer. ${ }^{31}$ We have estimated that the risk of contralateral breast cancer in this situation is about $30 \%$ by ten years after diagnosis. ${ }^{32}$ We have also estimated the risk of ovarian cancer in BRCA1 carriers after a diagnosis of breast cancer to be $13 \%$ in the tenyear period following a diagnosis of breast cancer. ${ }^{33}$

Emerging studies suggest that BRCA1 carriers may respond differently to chemotherapies than women without mutations. Studies done on BRCA1 carriers with breast cancer in Poland suggest that these women have a poorer than expected response to taxanes, but may benefit from cis-platinum. ${ }^{34}$

\section{Conclusion}

The discovery of the BRCA1 and BRCA2 genes in 1994 and 1995 has led to the introduction of genetic testing for cancer susceptibility into the practice of preventive oncology. There has been only limited testing done to 
date in Mexico. However, there is potential for genetic testing to reduce the burden of breast and ovarian cancer in Mexico, provided it can be introduced in an appropriate manner. The cost of testing must be relatively low; this could occur if founder mutations are present. If not then the cost genetic sequencing must come down to an acceptable level. It is necessary to define the criteria for genetic testing in Mexico, and then to publicise the recommendations and to develop a public health policy that results in the referral of appropriate candidates to qualified genetic testing centers. If a woman tests positive for a mutation, then an effort should be made to ensure that all unaffected women in her family are offered predictive testing.

Once a mutation is identified, strategies for prevention of breast and ovarian cancer that should be discussed with the patient include chemoprevention (tamoxifen), MRI screening (where available) and preventive surgery. In Mexico, MRI screening is not widely available, and it is likely that the greatest impact on cancer rates can be made with preventive surgery. Surgery is a one-time intervention and it offers the greatest degree of protection. Surgical oophorectomy is associated with an $80 \%$ reduction in the risk of ovarian cancer and up to a $60 \%$ reduction in breast cancer. Preventive mastectomy reduces the risk of breast cancer by greater than $90 \%$. If surgery is declined, tamoxifen is a good alternative. The best approach is a multidisciplinary clinic involving the geneticist, a genetics counsellor a medical oncologist, and surgeon.

\section{References}

I. Metcalfe K, Finch A, Poll A et al. Breast Cancer Risks in Women with a Family History of Breast or Ovarian Cancer who have Tested Negative for a BRCAI or BRCA2 Mutation Br J Cancer 2008 Dec. 16 (Epub ahead of print).

2. Antoniou A, Pharoah PDP, Narod S, Risch HA, Eyfjord JE, Hopper JL et al.Average risks of breast and ovarian cancer associated with BRCAI or BRCA2 mutations detected in case Series unselected for family history: a combined analysis of 22 studies. Am J Hum Genet 2003;72: I I 17- I I 30. 3. Narod SA, Foulkes WD. BRCAI and BRCA2: 1994 and beyond. Nat Rev Cancer 2004;4:665-676.

4. Foulkes WD, Steffanson IM Chappuis PO, Begin LR, Goffin JR, Wong N et al. Germline BRCAI mutations and a basal epithelial phenotype in breast cancer.J Natl Cancer Inst 2003;95: I 482- I 485.

5. Lakhani SR, Reis-Filho JS, Fulford L, Penault-Llorca F, van derVijer M, Parry $S$ et al. Prediction of BRCAI status in patients with breast cancer using estrogen receptor and basal phenotype. Clin Cancer Res 2005; I I: $5175-5180$.

6. Struewing J, Hartge P,Wacholder S, Baker SM, Berlin M, McAdams M et al. The risk of cancer associated with specific mutations of BRCAI and BRCA2 among Ashkenazi Jews. N Engl J Med 1997;336: I 40 I- 4008. 7. Risch H, McLaughlin J, Cole DE, Rosen B, Bradley L, Fan I et al. Population BRCAI and BRCA2 mutation frequencies and cancer penetrances: a kin-cohort study in Ontario, Canada.J Natl Cancer Inst 2006;98:1694-1706.

8. Warner E, Foulkes WD, Goodwin P, Meschino W, Blondal J, Patterson C, et al. Prevalence and penetrance of BRCAI and BRCA2 gene mutations in unselected Ashkenazi Jewish women with breast cancer.J Natl Cancer Inst 1999;91:124|-1247.

9. Tonin PN, Mes-Masson AM, Futreal PA, Morgan K, Mahon M, Foulkes WD et al. Founder BRCAI and BRCA2 mutations in French Canadian breast and ovarian cancer families. Am J Hum Genet 1998;63:| I34I-I35I. 10. Tonin P,Weber B, Offit K, Couch F, Rebbeck TR, Neuhausen S et al. Frequency of recurrent BRCAI and BRCA2 mutations in Ashkenazi Jewish breast cancer families. Nat Med 1996;2: I 179-I 183.

II. Gorski T, Byrski T, Huzarski T, Jakubowska A, Menkiszak J, Gronwald J et al. Founder mutations in the BRCAI gene in Polish families with breastovarian cancer. Am J Hum Genet 2000;66:1963-1968.

12. Calderón-Garcidueñas AL, Ruiz-Flores P, Cerda-Flores RM, BarreraSaldaña HA. Clinical follow-up of Mexican women with early-onset of breast cancer and mutations in the BRCAI and BRCA2 genes. Salud Publica Mex 2005; 47: I I0-II5.

13. Ruiz-Flores P, Sinilnikova OM, Badzioch M, Calderon-Garcidueñas AL, Chopin S, Fabrice $O$ et al. BRCAI and BRCA2 mutation analysis of earlyonset and familial breast cancer cases in Mexico. Hum Mutat 2002;20: 474-475.

14. Gomes MC, Costa MM, Borojevic R, Monteiro AN, Vieira R, Koifman $S$ et al. Prevalence of BRCAI and BRCA2 mutations in breast cancer patients from Brazil. Breast Cancer Res Treat 2007; 103: 349-353. 15. Dufloth RM, Carvalho S, Heinrich JK, Shinzato JY, dos Santos CC, Zeferino LC et al.Analysis of BRCAI and BRCA2 mutations in Brazilian breast cancer patients with positive family history. Sao Paulo Med J 2005; 123:192-197.

16. Torres D, Rashid MU, Gail F, Umana A, Rameli G, Robeldo JF et al. High proportion of BRCAI/2 founder mutations in Hispanic breast/ovarian cancer families from Colombia. Breast Cancer Res Treat 2007; 103: 225-232. 17. Jara L,Ampuero S, Santibáñez E, Seccia L, Rodríguez J, Bustamante M et al. BRCAI and BRCA2 mutations in a South American population. Cancer Genet Cytogenet 2006;166:36-45.

18. Gallardo M, Silva A, Rubio L,Alvarez C, Torrealba C, Salinas M et al. Incidence of BRCAI and BRCA2 mutations in 54 Chilean families with breast/ovarian cancer, genotype-phenotype correlations. Breast Cancer Res Treat 2006; 95: 8I-87.

19. Rodriguez RC, Esperon AA, Ropero R, Rubio MC, Rodriguez R, Ortiz RM et al. Prevalence of BRCAI and BRCA2 mutations in breast cancer patients from Cuba. Fam Cancer 2008;7: 275-279.

20.Vogel KJ,Atchley DP, Erlichman J, Broglio KR, Ready KJ,Valero V et al. BRCAI and BRCA2 genetic testing in Hispanic patients: mutation prevalence and evaluation of the BRCAPRO risk assessment model.J Clin Oncol 2007; 25: 4635-464I.

21. John EM, Miron A, Gong G, Phipps Al, Felberg A, Li FP et al. Prevalence of pathogenic BRCAI mutation carriers in 5 US racial groups. JAMA 2007; $298 ; 2869-2876$.

22. Weitzel JN, Lagos V, Blazer KR, Nelson R, Ricker C, Herzog J et al. Prevalence of BRCA mutations and founder effect in high-risk Hispanic families. Cancer Epi Biomarkers Prev. 2005; I4:1666-1671.

23. Weitzel JN, Lagos VI, Herzog JS, Judkins T, Hendrickson B, Ho JS et al. Evidence for common ancestral origin of a recurring BRCAI genomic rearrangement identified in high-risk Hispanic families. Cancer Epi Biomarkers Prev 2007;16:1615-1620.

24. Finch A, Beiner M, Lubinski J, Lynch HT, Moller P, Rosen B et al. Salpingo-oophorectomy and the risk of ovarian, fallopian tube, and peritoneal cancers in women with a BRCAI or BRCA2 Mutation. JAMA. 2006;296: 185-192.

25. Eisen A, Lubinski J, Gronwald J, Moller P, Lynch HT, Klijn J et al. Hormone therapy and the risk of breast cancer in BRCAI mutation carriers. J Natl Cancer Inst 2008; 100:1361-1367. 
26. Gronwald J, Tung N, Foulkes WD, Offit K, Gershoni R, Daly M et al. Tamoxifen and contralateral breast cancer in BRCAI and BRCA2 carriers: an update. Int J Cancer 2006; I I8:228I-2284.

27. Metcalfe KA, Lubinski J, Ghadirian P, Lynch H, Kim-Sing C, Friedman E et al. Predictors of contralateral prophylactic mastectomy in women with a BRCAI or BRCA2 mutation: the Hereditary Breast Cancer Clinical Study Group.J Clin Oncol. 2008; 26:1093-1097.

28. Jernström $H$, Lubinski J, Lynch $H T$, Ghadirian $P$, Neuhausen $S$, Isaacs $C$ et al. Breast-feeding and the risk of breast cancer in BRCAI and BRCA2 mutation carriers. J Natl Cancer Inst 2004;96:1094-1098.

29. McLaughlin JR, Risch HA, Lubinski J, Moller P, Ghadirian P, Lynch $\mathrm{H}$ et al. Reproductive risk factors for ovarian cancer in carriers of BRCAI or BRCA2 mutations: a case-control study. Lancet Oncol. 2007;8:26-34. 30. Warner E, Plewes DB, Hill KA, Causer PA, Zubovits JT, Jong RA et al. Surveillance of $\mathrm{BRCAI}$ and $\mathrm{BRCA} 2$ mutation carriers with magnetic resonance imaging, ultrasound, mammography, and clinical breast examination. JAMA. 2004; 292: I3 17-1325

31. Metcalfe KA, Birenbaum-Carmeli D, Lubinski J, Gronwald J, Lynch H, Moller $\mathrm{P}$ et al. International variation in rates of uptake of preventive options in BRCAI and BRCA2 mutation carriers. Int J Cancer 2008; I 22:20I7-22.

32. Metcalfe K, Lynch HT, Ghadirian P, Tung N, Olivotto I, Warner E et al. Contralateral breast cancer in BRCAI and BRCA2 mutation carriers. J Clin Oncol. 2004; I5:2328-2335.

33. Metcalfe KA, Lynch HT, Ghadirian P, Tung N, Olivotto IA, Foulkes WD et al. The risk of ovarian cancer after breast cancer in BRCAI and BRCA2 carriers. Gynecol Oncol 2005;96:222-226.

34. Byrski T, Huzarski T, Dent R, Gronwald J, Zuziak D, Cybulski C et al. Response to neoadjuvant therapy with cisplatin in BRCAI-positive breast cancer patients. Breast Cancer Res Treat 2008 Jul 23. (Epub ahead of print). 